\title{
Declaración de Quito
}

\section{Primer Encuentro Latinoamericano de Comunicación Alternativa y Popular - Abril 1993}

\section{Contexto actual de la comunicación}

En momentos que Latinoamérica vive la más grave crisis económica y social de su historia, marcada por la imposición de políticas neoliberales, la vigencia de una Guerra de Baja Intensidad y la promoción de democracias controladas, a lo largo del continente, uno de los derechos más sistemáticamente violentados es el derecho a la comunicación, en el sentido de poder acceder y transitar por ese espacio.

En este contexto se ha intensificado la privatización y concentración de los medios de comunicación en pocas manos, al tiempo que se incrementa el cierre de medios de comunicación y la persecución de comunicadores sociales por defender las causas populares.

Simultáneamente, nuevos actores acceden a los medios de comunicación, generando opinión y sensibilizando a los ciudadanos. Ejemplo de ello lo constituyen movimientos tales como el desarrollado en pro de los derechos humanos, del medio ambiente, de la mujer y de los grupos étnicos.

A nivel internacional en tanto, se está consolidando un proceso de globalización de la información, en el que juega un papel determinante la irnupción de nuevas tecnologías.

\section{La Comunicación, un derecho del pueblo}

Siempre se ha entendido el derecho a la comunicación como una atribución vinculada al derecho de las personas a informar y ser informadas, así como también el de ejercer la libre expresión del pensamiento.

Esta atribución constituye, uno de los más fundamentales derechos de todo ser humano, el cual es reivindicado en todos los tratados que al respecto han suscrito las naciones.

Sin embargo, la democratización de la comunicación debe también garantizar el acceso de todas las personas y grupos sociales a los medios de comunicación en igualdad de oportunidades, algo todavía pendiente de legislar en la mayoría de países del mundo.

No obstante, hay que considerar que para la democratización de los medios de comunicación entran en juego las distintas realidades de los países de nuestra región, así como sus legislaciones, sistema de tenencia de los medios, capacidad de los recursos que estos poseen, entre otros.

\section{III. ¿Qué supone una comunicación democrática?}

a. Pluralismo: entendido como el ejercicio activo de los diversos sectores sociales en los procesos de comunicación, dentro de un marco ético y democrático.

b. Participación: en donde deben actuar todos los actores sociales, ejerciendo su derecho a informar, ser informado y dar libremente su opinión, y también los ciudadanos como consumidores de la comunicación para que con sus criterios puedan influir en la selección y elaboración de los contenidos de los mensajes de los medios.
También los actores de la comunicación, periodistas y productores deben involucrarse en la elaboración de la política editorial de su medio y/o en la propiedad de los mismos.

c. Una función social: los medios de comunicación deben cumplir su responsabilidad social, es decir, en su proyección deben dar mucha importancia a las problemáticas de interés general.

d. El debate democrático: a los medios de comunicación democráticos les corresponde fomentar la cultura del debate como uno de los métodos para alentar la participación y el espíritu crítico y reflexivo

\section{Vigencia de la comunicación alternativa y popular}

En este marco, es evidente que mantiene vigencia y se vigoriza el trabajo que ha venido desarrollando la corriente de comunicación alternativa y popular, tanto en los ámbitos masivos y grupales, como en los medios propios o en espacios de otros medios.

Hoy, además de transmitir información, la comunicación altemativa y popular también genera estrategias y acciones en y desde los movimientos sociales, redes, legislaciones, eventos, etc, incidiendo significativamente en el proceso de democratización de la comunicación en su conjunto.

En este sentido, la democratización de la comunicación impone a la corriente alternativa cuando menos dos retos

1. Defender y ampliar los espacios de la comunicación alternativa y popular.

2. Estrechar los vínculos con todos los sectores sociales en la lucha por sociedades más democráticas.

\section{La democratización de la comunicación}

La ofensiva neliberal ha repercutido también en el plano cultural, imponiendo un modelo individualista y competitivo que enfrenta a todos contra todos para sobrevivir. Para ello se ha reforzado el control sobre los medios y sistemas de comunicación social. Así, cada vez más resulta evidente que la concentración de los medios de comunicación social en pocas manos obstaculiza el desarrollo democrático de nuestros países, en tanto bienes públicos, los medios y sistemas de comunicación deberían ser controlados democráticamente por toda la sociedad.

También, el avance de las trasnacionales de la información protegidas y apoyadas por la expansión del libre comercio, agrede la identidad nacional de nuestros pueblos y reafirma la concentración moonpólica y excluyente de los medios de comunicación.

Para contrarrestar esta situación, los participantes del Encuentro Latinoamericano de Comunicación Alternativa y Popular decidimos promover la articulación de un amplio movimiento en favor de la democratización de la comunicación, como parte de la democratización global de la sociedad. 